\title{
Disputa eleitoral e estratégias de campanha na internet: padrões de uso dos websites pelos candidatos em 20 I 2
}

\author{
Michele Goulart Massuchin \\ Camilla Quesada Tavares'
}

\begin{abstract}
Resumo
$O$ artigo analisa o uso que os candidatos a prefeito nas eleições de 2012 fizeram da internet ao longo do período eleitoral. O objetivo do estudo é identificar os padrões e diferenças no uso dessa ferramenta a partir da observação de duas características específicas: estratégias e tematização. A proposta é observar esse espaço de campanha conforme o conteúdo disponibilizado e não por meio da presença ou ausência de potencialidades interativas e participativas. Os dados apresentados aqui são resultados parciais de uma pesquisa que está em andamento, sendo que foram incluídas neste artigo, de maneira comparativa, as campanhas realizadas pelos principais candidatos de três capitais: São Paulo, Curitiba e Rio de Janeiro. A metodologia usada é quantitativa de análise de conteúdo e ao todo foram analisados 1268 posts, o que representa o total de atualizações do período eleitoral para os oito candidatos das três capitais. No que diz respeito à tematização, predominam os textos que enfatizam a campanha eleitoral factual. Já sobre as estratégias, a campanha online é usada, majoritariamente, para enfatizar as propostas de políticas públicas e transpor a campanha realizada em outras esferas. As demais estratégias aparecem dispersas entre os candidatos.
\end{abstract}

Palavras-chave: internet; campanha online; eleições 2012; estratégias de campanha; candidatos.

\section{Sobre as autoras}

Michele Goulart Massuchin é doutoranda em Ciência Política na Universidade Federal de São Carlos (UFSCar). Membro do Grupo de Pesquisa em Comunicação Política, Partidos e Eleições da UFSCar e do Grupo de Pesquisa em Comunicação Política e Opinião Pública (CPOP) da UFPR. E-mail: mimassuchin@ gmail.com

Camilla Quesada Tavares é professora do Departamento de Jornalismo da Universidade Estadual de Ponta Grossa (UEPG) e mestre em Ciências Sociais Aplicadas pela UEPG. Membro do Grupo de Pesquisa Jornalismo e Política: representações e atores sociais, e do Grupo de Pesquisa em Mídias Digitais (GEMIDI), ambos da UEPG. E-mail: camilla.tavares8@gmail.com 


\begin{abstract}
This article examines the use of the internet by candidates for mayor in the 2012 elections during the electoral period. The objective of this study is to identify the patterns and differences in the use of this tool from the observation of two specific features: strategies and theme.The proposal is to observe this space of campaign from content and not by the presence or absence of interactive and participatory potential. The dates presented here are partial results of a research that is in progress and were included in this article, in a comparative way of the campaigns of three capitals: São Paulo, Curitiba and Rio de Janeiro. The methodology used is quantitative content analysis and were analyzed 1268 posts from eight candidates. About the theme, many of the texts emphasize factual campaign. About the strategies, online campaign is used, mainly, to emphasize the public policy proposals and approach the campaign in other spheres. Other strategies appear dispersed among the candidates.
\end{abstract}

Keywords: internet; online campaign; elections 2012; strategies of campaign; candidates.

Artigo recebido em 7 de agosto de 20I4. Aprovado em 30 de novembro de 2014.

\title{
Introdução
}

Este $\operatorname{artigo~}^{1}$ discute os padrões e diferenças no uso que os candidatos a prefeito fizeram da internet - mais especificamente de seus websites - durante a campanha eleitoral de 2012 no Brasil, considerando dois aspectos: a tematização e as estratégias de discurso, tomando por base os textos informativos apresentados geralmente na seção "notícias", a qual é atualizada periodicamente. Apresenta-se aqui parte dos dados utilizados em uma pesquisa que está em andamento e tem por objetivo identificar as principais características da campanha online. Para observar se existe ou não algum padrão de uso, assim como as diferenças entre candidatos quanto à apropriação do novo espaço de campanha, optou-se aqui por apresentar uma análise comparativa considerando os principais candidatos a prefeito de três capitais: Curitiba, São Paulo e Rio de Janeiro.

1. Uma versão inicial deste texto foi apresentada no IX Encontro da Associação Brasileira de Ciência Política (ABCP) em agosto de 2014. A pesquisa que originou este artigo é financiada pela Fundação de Amparo à Pesquisa do Estado de São Paulo (FAPESP). 
Para tratar das campanhas online nesses três cenários eleitorais e estudar suas proximidades e diferenças serão utilizadas informações sobre o conteúdo das postagens. A literatura indica que nas campanhas, de modo geral, os candidatos utilizam determinadas estratégias e temas conforme os pleitos se estruturam (Figueiredo et al., 1998), sendo que também variam de acordo com o perfil de cada um (com ou sem carreira política, por exemplo), assim como da sua posição nas pesquisas eleitorais. Esta pesquisa pretende identificar como os candidatos se posicionam na campanha online levando em consideração essas características já discutidas pela literatura, mas agora considerando um espaço específico de campanha que é a internet. Embora seja um espaço recente usado pelos políticos no Brasil, os candidatos se apropriam dele para se aproximar de seus eleitores e difundir informações políticas que possam ter resultados positivos para a disputa do pleito. Portanto, para o desenvolvimento deste artigo optou-se por analisar duas variáveis: tematização e estratégias. No primeiro caso, o objetivo é verificar quais temáticas são mais debatidas pelos candidatos em seus websites, a fim de classificar a agenda temática da campanha (Figueiredo et al., 1998), visto que há tradição de que as campanhas mediadas pelos meios de comunicação tendam a ser destinadas para construção da imagem do candidato (Cervi e Massuchin, 2011) ao invés de discutir temas de interesse público (tomando por base os estudos referentes ao horário eleitoral brasileiro). No que tange às estratégias, elas são intrínsecas ao jogo político. Nas campanhas, os candidatos acabam evidenciando, por meio de suas estratégias, a ideologia, o desempenho do governo (enfatizando ou criticando), a imagem do candidato, a segmentação do voto entre outros fatores, etc. As estratégias partem da lógica dos mundos possíveis (Figueiredo et al., 1998) e estão baseadas no contexto dos eleitores no qual a campanha pretende atingir e depende do posicionamento do candidato na disputa. Ou seja, existe uma série de fatores - exógenos à campanha em si - que interferem no conteúdo produzido e publicizado. $\mathrm{O}$ ambiente da campanha, citando Stromer-Galley (2014), é que constrói a mensagem de campanha.

A proposta deste estudo, então, é observar esse espaço de campanha conforme o conteúdo disponibilizado, e não por meio da presença ou ausência de potencialidades interativas e 
participativas ${ }^{2}$. Sendo assim, algumas indagações serão respondidas ao longo do artigo a partir da observação das postagens realizadas durante os três meses de campanha: em que medida os candidatos se aproximam ou se distanciam no que diz respeito à campanha online? É possível perceber que as campanhas em um mesmo cenário eleitoral seguem determinado padrão temático e estratégico? Como a internet compõe o ambiente das campanhas eleitorais a partir do conteúdo disponibilizado pelos candidatos?

Para responder essas questões iniciais, serão analisadas 1268 postagens de conteúdo informativo referentes aos principais candidatos das três capitais selecionadas neste artigo. Ressalta-se que não se trata de uma amostra, mas de todo o conteúdo informativo diário disponibilizado nos websites durante o período Nos textos foram consideradas diversas características, sendo que aqui serão trabalhadas duas delas a partir da análise quantitativa de conteúdo: a tematização e as estratégias. O marco teórico que embasa esta pesquisa está situado nas discussões sobre o processo de modernização das campanhas e a inclusão da internet como espaço de campanha (Stromer-Galley, 2014; Mazzoleni, 2010; Norris, 2001; Mancini e Swanson, 1995). Além disso, num outro eixo, discutem-se as campanhas eleitorais como momentos estratégicos em que os candidatos se utilizam de diferentes estratégias pensadas previamente e que têm relação com o contexto da campanha (Albuquerque, 1999).

Por fim, este trabalho parte de duas hipóteses principais: 1) Os candidatos - inclusive do mesmo cenário de disputa - agem de maneira distinta na campanha na internet, sendo que as características de perfil, carreira política e a polaridade partidária podem ser possíveis explicações para tais comportamentos diferenciados; 2) Embora a internet seja considerada como um espaço de transposição das campanhas realizadas em outras esferas, também tem a função de ser propositiva. No próximo tópico apresenta-se uma breve discussão teórica e na sequência é feita a análise dos dados.

2. Essa é uma linha de estudo que vem recebendo bastante atenção de pesquisadores nacionais e internacionais - nos últimos anos. Autores que se destacam nesse tipo de abordagem são: Iasulatis (2013; 2007); Marques (2012); Braga (2012; 2007); Braga e Nicolás (2009); Sampedro e Perés (2009), Vaccari (2008), Gibson e Ward (2000). 


\section{Modernização das campanhas e o uso da internet em período eleitoral}

O período que antecede as eleições é marcado pela circulação de informações políticas provenientes tanto dos candidatos e partidos quanto dos meios de comunicação. As primeiras são distribuídas pela própria elite política, sem que haja influência de fatores exógenos, ou seja, há autonomia na produção de conteúdo e assim é possível utilizar-se de diferentes estratégias de discurso da maneira que os marqueteiros acham mais adequado. Já as informações políticas distribuídas pelos meios de comunicação comerciais passam por um processo de enquadramento e filtragem, feita por esses atores externos à esfera política. Dessa forma, cada tipo de informação tem uma função durante o período eleitoral e partem de atores distintos em direção à sociedade. O objetivo desta pesquisa, portanto, não é olhar para a totalidade de informação distribuída, mas sim estudar uma pequena parte da campanha feita exclusivamente pelos candidatos e partidos. Ela possui uma função diferente do segundo modelo, pois enquanto a elite política tem a função de persuadir o eleitor para obter votos com a campanha por meio da propaganda, os meios de comunicação possuem a função mais informativa (Mazzoleni, 2010).

O eleitor que chega ao período de campanha ainda sem ter definido o voto se utiliza deste momento e das informações disponibilizadas para decidir em quem vai votar. Trata-se dos eleitores não partidários ou voláteis. Sendo assim, a propaganda política feita por candidatos e partidos tem por objetivo atingir um tipo específico de eleitor que tem crescido mais nos últimos anos, inclusive ganhando destaque na literatura (Manin, 1995). O foco da campanha eleitoral, seja do sendo o HGPE, da campanha face a face e de todos os demais espaços onde é possível trabalhar com determinadas estratégias, é atingir, direta ou indiretamente, os eleitores indecisos. É para esse eleitor que o candidato se apresenta, discute temas, profere discursos mais ideológicos ou pragmáticos, escolhe uma estratégia persuasiva ou outra.

Em função de fatores como a incorporação da internet na campanha e o enfraquecimento das bases ideológicas dos partidos, a forma de fazer campanha por parte dos partidos foi mudando e alguns elementos podem ser usados para caracterizar o processo de modernização. Mancini e Swanson (1995) fazem uma caracterização 
das campanhas modernas, mas sem apresentar um marco transitório como Norris (2001) e Mazzoleni (2010). Os autores ressaltam que o primeiro ponto que caracteriza esse novo cenário é a personalização da política, onde a imagem dos candidatos possui mais visibilidade que os próprios partidos, sendo enfatizadas questões pessoais e menos ideológicas ${ }^{3}$. Dessa maneira, a primeira mudança percebida no que eles chamam de modernização das campanhas eleitorais é a menor partidarização dos eleitores e o enfraquecimento das bases ideológicas (Mancini e Swason, 1995). Outra característica das campanhas modernas é que os partidos acabam dividindo cada vez mais a função de informar o público sobre questões políticas com os meios de comunicação. Se nas campanhas tradicionais as informações eram restritas àquelas fornecidas pelos partidos, inclusive por meio de mecanismos como cartazes, jornais partidários e publicidades, com o desenvolvimento dos meios de massa há um aumento da quantidade de informações sendo distribuídas também pela mídia comercial. Ela contribui com o processo de formação da opinião pública e do debate público, tendo uma função antes exercida unicamente pelos partidos (Manin, 1995; Mancini e Swanson, 1995). Mas isso não significa que os partidos deixaram de fazer campanha. Pelo contrário se apropriam de novos espaços para marcar território e enfatizar o objetivo de angariar votos e ganhar a atenção dos eleitores.

Outra autora que apresenta uma descrição do processo evolutivos das campanhas é Norris (2001). A autora subdivide as campanhas ocidentais em três grandes períodos. O primeiro momento é definido como pré-moderno, e data as campanhas realizadas até 1950; a segunda fase seria o período moderno, e se refere à segunda metade do século XX, onde o auge das campanhas é a televisão, que substitui o contato face a face e se transforma no cenário de competição eleitoral; por fim, a terceira fase, chamada por Norris (2001) de pós-moderna, trata de uma total profissionalização de todas as atividades da campanha. Além disso, há segmentação das mensagens e estudos mais aprofundados, baseando-se nas pesquisas de opinião pública, para

3. A discussão sobre o declínio dos partidos e enfraquecimento das bases ideológicas não é consenso na literatura. 
identificar as características do eleitorado e como atingi-lo por meio das estratégias usadas pelos profissionais.

É neste contexto da terceira fase apresentada por Norris (2001) que há a citação dos novos meios como ferramenta eleitoral. Segundo a autora, as novas tecnologias passam a ser usadas no marketing, pois teriam determinadas características relevantes para contatar o eleitor (Norris, 2000).

Enquanto Mancini e Swanson (1995) não citavam ainda a ascensão da internet como mecanismo nas eleições - o que também não era feito por Manin (1995) - Mazzoleni (2010) já ressalta a inclusão dessa nova mídia, seguindo a perspectiva de Norris (2001), de que os novos meios são ferramentas que passam a ser utilizadas pela elite política para fazer campanha segmentada entre seus eleitores. Da mesma maneira, mostrando o papel da internet no avanço do processo de modernização dos processos eleitorais, Blumler e Kavanagh (1999) já identificam alguns indícios de como essa ferramenta passou a ser utilizada, no que o autor chama de terceira fase da comunicação política que seria muito mais complexa do que as demais. Blumler e Kavanagh (1999) dizem que ao usar a internet, os candidatos tentam uma nova maneira de se aproximar do eleitorado. Ressalta-se que se trata de um eleitorado que possui interesse por política - pelo menos para acessar os sites - e que procura definir seu voto a partir das informações disponíveis durante o período de campanha. Além disso, a internet e os sites dos candidatos podem ser acessados pelo eleitor, que serve como um formador de opinião e que faz com que aquela informação transcenda o espaço da rede.

A internet foi incorporada às campanhas de 1995 e 1996, nos Estados Unidos e Inglaterra, respectivamente (Dader, 2009). Formase um novo campo de pesquisa que passou a ser conhecido como cibercomunicacão política (Dader e Ayuso, 2008). Na primeira década do século XXI, o que não falta na literatura são estudos, cada vez mais amplos e nos mais diversos contextos, estudando os usos dos novos meios como ferramenta de campanha em períodos eleitorais nos mais diversos países (Braga e Nicolas, 2011; Dader, 2009; Gibson e Ward, 2000; Newell, 2001; Vaccari, 2008).

Segundo Dader (2009) assim que a internet se destaca entre os meios de comunicação, os partidos e candidatos já se apropriam desse espaço sem nem mesmo saber exatamente a função que podem ter nas campanhas. Na década de 1990 o uso dos websites 
ainda era muito restrito, mas logo nos anos 2000 já havia, segundo Dader (2009), 1250 sites de partidos de diversos países na internet, o que significava um avanço em termos de uso. $\mathrm{Na}$ Espanha, por exemplo, a campanha de 2000 é considerada como um marco no uso generalizado dos websites (Dader, 2009). Já a partir de 2007, a internet tende a estar mais consolidada em diversos países e é possível perceber o impacto dos websites nas campanhas, já que eles deixam de ser instrumentos marginais e passam a integrar a dinâmica eleitoral combinados com outros meios (Dader, 2009). Embora sozinhos pareçam insignificantes, atuam de forma ativa e significativa em parceria com outros veículos, compondo a rede de campanha de candidatos e partidos, podendo servir para reforçar e auxiliar a campanha realizada em outras esferas.

\section{A nova ferramenta de campanha: os estudos empíricos aplicados ao caso brasileiro}

Os estudos sobre internet têm o ano de 1996 como marco da presença dessa ferramenta em campanhas, pois já há candidatos que aderem à rede nas eleições americanas: $71 \%$ candidatos a senadores, $68 \%$ dos deputados e $68 \%$ dos governadores possuíam website. No Brasil, Nicolás, França e Braga (2010) indicam o crescente uso dessa nova ferramenta a cada período eleitoral brasileiro. Nessa perspectiva analítica que enfatiza o uso que a elite política faz da internet, há uma grande diversidade de pesquisas desenvolvidas desde o pleito de 2002 e abordando as mais diferentes ferramentas: websites, blogs, Twitter, Facebook entre outras. Uma pesquisa realizada por Braga, Nicolás e Becher (2013) monitorando o uso da internet nas eleições de 2010 para os governos estaduais e para o senado federal mediu como se deu o uso da ferramenta em mais uma eleição no período pós-efeito Obama. A análise contou com um corpus de 406 candidatos e concluiu que pela primeira vez as pesquisas não encontraram grandes diferenças regionais no uso da rede no Brasil e a ampla difusão das redes sociais, substituindo o possível debate por meio de fóruns, chats e outros meios presentes em websites. Segundo Marques (2004), a campanha feita na internet tem fins eleitoreiros, mas também tem o objetivo de trazer os eleitores de volta às discussões, apresentando informações para debate. Além disso, como já foi apontado, trata-se de uma ferramenta em que os partidos e 
candidatos podem agir diretamente sem a mediação do jornalismo para divulgar suas próprias informações (Marques, 2004).

Em um trabalho realizado por Marques, Silva e Matos (2011) são investigadas as estratégias de campanha no Twitter de José Serra no período eleitoral de 2010. Embora não se trate de análise de website, esta pesquisa também se preocupa com as estratégias de campanha, pretendendo identificar se há alteração ou se mantém as formas de campanhas tradicionais de obter votos, já que as mídias sociais também seriam uma forma de captar poder político. Os autores concluem que são usadas as mesmas táticas do marketing tradicional das outras campanhas e que nas mensagens foi possível perceber a atuação da rede na formação da imagem do candidato e de uma rede de apoiadores.

A internet como fonte de informação também serve para dar espaço ao conteúdo não veiculado em outros meios como o HGPE, por exemplo, para evitar problemas com a Justiça Eleitoral (Marques e Sampaio, 2011). Embora ressaltem essa ideia de que os websites contribuem para aumentar o leque de informações políticas disponíveis, Marques e Sampaio (2011) mostram que o candidato precisa informar, mas também convencer, ou seja, agir estrategicamente. Já a pesquisa desenvolvida por Penteado e Fortunato (2011) observa uma parcela do conteúdo publicado em sites de partidos (PT, PV e PSDB) no período pré-eleitoral de 2010. Os autores analisam o tratamento dado ao tema 'energia' pelos sites e percebem a presença de estratégias diferentes, inclusive de campanha negativa e referente à atuação em gestões anteriores. Outra conclusão relevante foi que as estratégias dos sites seguiam aquelas usadas nos programas do HGPE, mostrando possíveis limitações da internet para promover um debate diferente daquele já presente em outras esferas.

Em um texto prévio das eleições de 2010, Braga (2010) observou que, embora houvesse muitas especulações quanto ao uso da internet durante a campanha, ainda se sabe muito pouco sobre quatro pontos que precisam ser pesquisados: a) como a internet influencia as escolhas dos candidatos e é usada nas convenções dos partidos; b) como ela é usada pelos candidatos a partir das estratégias discursivas de campanha e na construção da imagem; c) como são usados os espaços de participação; d) como está sendo a recepção por parte do eleitorado. Dessa forma, é possível, por meio desta pesquisa, tentar responder o segundo item apontado pelo autor. E, 
apesar da necessidade de estudos para acompanhar a evolução da ferramenta, Braga (2010) destaca o inegável papel da rede como fonte de informação política e do uso quase que generalizado entre os candidatos. Braga (2010) ressalta que, de modo geral, tanto nas pesquisas brasileiras quanto internacionais, os resultados estão abaixo da expectativa dos chamados 'otimistas'. Mas ao mesmo tempo a ferramenta tem sido usada pelos candidatos para complementar a campanha offline e os resultados do uso não são negativos, apenas mais próximo do que Domingués (2005) chama de ciberrealistas.

\section{Estratégias de campanha aplicadas para o estudo sobre internet e política}

Seja nas campanhas tradicionais ou modernas, ou até mesmo pósmodernas, candidatos e partidos tem por objetivo chegar ao poder por meio da obtenção de votos. Para isso, tentam obter visibilidade durante o período eleitoral e, a partir de determinadas estratégias, chamar a atenção daqueles que ainda não tenham feito a escolha de seu representante ou reafirmar as escolhas que já foram feitas previamente. A questão central da pesquisa é investigar o uso das estratégias na internet, sendo que para isso utiliza-se da literatura já existente, principalmente baseada em estudos de HGPE, spots, rádio e até mesmo das campanhas tradicionais. As estratégias partem da lógica dos mundos possíveis (Figueiredo et al., 1998) e estão baseadas no contexto dos eleitores que a campanha pretende atingir. Além disso, também dependem do posicionamento do candidato na disputa. Ou seja, existe uma série de fatores - exógenos à campanha em si - que interferem no conteúdo produzido e publicizado.

Se os candidatos empregam - por meio dos experts - estratégias de campanha em cada um dos meios que obtém para esta finalidade, estima-se que com a evolução da rede esse espaço também já seja usado com um determinado objetivo. Há uma série de características já discutidas pela literatura e outras que se pretende explorar nesta pesquisa. Entre as principais estão o partidarismo, o personalismo, a campanha negativa, a referência a realizações e cargos ocupados, agenda de campanha, campanha propositiva, uso de apoio de famosos/lideranças, apoio ao partido. Além disso, percebeu-se que aparecem outros tipos de comportamento como campanha meramente informacional e uso de pesquisas de intenção de voto para reafirmar 
a posição na disputa. Abaixo, apresenta-se uma breve discussão de algumas estratégias:

Campanhas personalistas: Uma das características da propaganda eleitoral que tem ganhado destaque entre os autores que discutem as campanhas modernas é o personalismo, isto é, o foco da propaganda no candidato e em suas características pessoais, deixando em segundo plano as questões partidárias. A personalização da política ocorre em função da necessidade que alguns partidos possuem em buscar uma autoridade política para que os indivíduos se identifiquem, e isso tem sido característica das campanhas modernas (Mancini e Swanson, 1995). Esse fenômeno, na perspectiva de Mazzoleni (2010) resulta do foco na imagem.

Campanhas partidarizadas: Embora sozinhos os partidos já sejam uma variável que possui impacto na decisão do voto, os candidatos podem usar da figura do partido para que os eleitores se identifiquem. No entanto, isso só é vantajoso para o candidato quando o partido tem um histórico relevante e esteja entre os objetivos construir a imagem atrelada a do partido. Embora não tenha sido encontrado nenhum estudo sobre estratégias partidárias e personalistas no conteúdo publicado nos websites, as pesquisas feitas no HGPE, como a de Dias (2009), mostram que a relação entre candidatos e partidos varia de um a outro, sendo que a autora encontrou maior interferência do partido na campanha do PSOL que do PSDB nas eleições de 2006.

Campanha negativa: Dependendo do contexto - tanto da disputa quanto do posicionamento do candidato - a propaganda negativa tem se tornado característica das campanhas. Ela tem ficado evidente na internet e marca uma mudança nas táticas de propaganda eleitoral. Esse tipo de campanha não é característico da internet, mas tem adentrado nesse espaço. O objetivo de desqualificar é colocar o outro candidato em uma posição inferior (Borba, 2012). Dader (2009) identificou, por exemplo, que já na campanha americana de 1996, esse tipo de estratégia ficava perceptível nos websites. $\mathrm{Na}$ Espanha, a campanha de 2008 na internet, por exemplo, também foi um exemplo da presença de propagandas negativas, segundo Sampedro e Perés (2009). No Brasil, um exemplo pode ser encontrado na análise de Borges e Aldé (2004) sobre a campanha de Serra e Ciro em 2002, que foi mais negativa na internet que no HGPE.

Campanha propositiva: As campanhas eleitorais podem ser definidas como o momento em que os partidos apresentam seus candidatos 
e tentam persuadir o eleitor indeciso, mas também é o período em que se colocam temas políticos e sociais para debate. Como define Albuquerque (1999), a discussão de problemas políticos encontra-se dentre as funções da propaganda eleitoral, pois o eleitor escolheria seu candidato conforme a proximidade com a plataforma política apresentada. Na campanha de 1989, as discussões temáticas foram centrais para a construção da campanha de Lula, já que o candidato abordou diversos assuntos, ao contrário de Collor, que usou pouco espaço para isso (Albuquerque, 1999). Este resultado contribui para reafirmar o pressuposto de que o uso de cada uma das estratégias depende do candidato, seu posicionamento na eleição e de outros fatores contextuais.

Patronos, aliados e apoiadores para formar a imagem: Dentre as estratégias de campanha também está a possibilidade de formar a própria imagem tendo o auxílio de patronos, aliados e apoiadores que aparecem ao lado do candidato como forma de dar credibilidade e apoio. Tavares (2013) em seu estudo sobre o uso do patrono nas campanhas de 2002, 2006 e 2010, mostra que essa é uma figura muito presente no HGPE, principalmente na eleição de Dilma Rousseff (PT). Mas para além do que a autora define como patrono, há também os aliados, as lideranças e os apoiadores famosos que entram na campanha com o intuito de auxiliar o candidato a obter prestígio e visibilidade. Embora o estudo de Tavares (2013) tenha como foco o HGPE, é possível que essa estratégia seja usada também na internet. O tópico seguinte apresenta os cenários estudados - Curitiba e São Paulo - assim como os principais fatos da campanha e a evolução dos candidatos na disputa.

\section{Metodologia e desenho da pesquisa}

A pesquisa utiliza a metodologia quantitativa de análise de conteúdo, sendo que a coleta de dados foi realizada durante todo o período eleitoral para o primeiro turno das eleições de 2012 - do dia seis de julho a seis de outubro. O foco da análise é o conteúdo disponibilizado diariamente pelos candidatos e suas assessorias neste espaço de campanha, ou seja, as postagens de conteúdo informativo realizadas no espaço de "notícias da campanha". Para a composição do banco de dados, as notícias foram coletadas diariamente pela 
primeira autora deste trabalho ${ }^{4}$. Os dados provenientes das coletas foram sistematizados em um banco de dados, sendo que as categorias e variáveis foram previamente selecionadas e estruturadas por meio de um livro de códigos que guiou o trabalho de análise e permitiu que cada postagem fosse analisada de acordo com parâmetros estabelecidos anteriormente. No livro de código construído para a pesquisa há uma descrição detalhada do que cada variável/categoria engloba, o que permite enquadrar as postagens seguindo sempre os mesmos critérios, o que dá confiabilidade e rigor metodológico à pesquisa. Após a sistematização, os dados no Excel são verificados antes da análise. Além dos textos, foram salvos ainda os materiais visuais presentes nas postagens, embora a análise desse conteúdo não seja o enfoque deste artigo.

$\mathrm{O}$ artigo propõe um estudo comparativo a partir de dados das campanhas online realizadas pelos principais candidatos de três capitais brasileiras: Curitiba, São Paulo e Rio de Janeiro. Nas duas primeiras capitais têm-se dados de três candidatos (Luciano Ducci, Gustavo Fruet e Ratinho Junior em Curitiba e Celso Russomanno, José Serra e Fernando Haddad em São Paulo) e na última de dois (Marcelo Freixo e Eduardo Paes). A escolha se deu em função de serem os candidatos mais bem posicionados nas pesquisas de opinião pública. Ao todo foram analisados 1268 textos postados nos websites, que correspondem ao universo total das postagens.

A análise está centrada na observação comparativa a partir de duas variáveis específicas: tematização da campanha e estratégias de discurso. Trabalha-se com uma categorização de 20 possíveis temas. Caracteriza-se uma postagem como temática sempre que uma publicação tem como pano de fundo algum tema específico, não tratando apenas da campanha eleitoral e seu cotidiano. Dentro da variável "tema", foram elencados diferentes assuntos que poderiam ser encontrados numa campanha eleitoral municipal. A descrição de cada tema específico que poderia ser encontrado nas postagens foi

4. Alguns softwares foram testados para fazer a coleta dos conteúdos disponibilizados nos websites. Porém, eles apresentaram algumas falhas, e por isso optou-se pela coleta manual. O conteúdo então foi salvo e analisado posteriormente, com o final da campanha. Os dados coletados eram sistematizados em planilhas do Excel para que depois fosse possível trabalhar com os cruzamentos de variáveis no software estatístico SPSS. 
baseada nas pesquisas realizadas com mídias tradicionais pelo Grupo de Pesquisa em Comunicação Política e Opinião Pública da UFPR, sendo que para a análise da disputa municipal novos temas foram agregados. Ressalta-se que cada texto é enquadrado conforme um tema específico, que recebe mais ênfase em determinada postagem. Quando a postagem trata de uma mescla de temas, é enquadrada na categoria "conjunto de temas".

Para esclarecer o que cada tema engloba, descreve-se brevemente o que cada categoria da variável agrega: (a) Campanha Eleitoral diz respeito a textos sobre a campanha, eventos, programação, agenda do candidato, etc.; (b) Partidos Políticos engloba as postagens que se referem à instituição partidária, levantando questões, normas e informações que envolvem o partido; (c) Político Institucional considera os textos sobre questões que ocorrem nas três esferas de governo, sem relação com a campanha propriamente dita; (d) Econômica concentra problemas econômicos e políticas para o setor; (e) Saúde abrange políticas para a saúde, problemas na saúde pública, propostas para saúde da mulher, das crianças, dos idosos; (f) Educação enquadra as entradas sobre políticas de Educação, universidades, escolas, creches, todas as instituições de ensino; (g) Mobilidade Urbana e Transporte Público corresponde a políticas de urbanização, trânsito, metrô, ônibus, criação de ciclovia, aumento de obras nas ruas, etc.; (h) Ações para Grupos Minoritários consideram políticas e informações sobre grupos minoritários, tais como mulheres, homossexuais, idosos, etc.; (i) Meio Ambiente engloba as políticas ambientais e problemas que afetam o meio-ambiente; (j) Segurança Urbana diz respeito a ações de segurança e contra a violência, etc.; $(\mathrm{k})$ Ações de Combate à Miséria aparecem quando o post trata de programas sociais, assistência social, segurança alimentar, entre outros; (1) Questões Trabalhistas enquadram reivindicações de trabalhadores e ações para a geração de emprego; (m) Habitação concentra as postagens sobre criação de moradias, realocação de famílias, melhoramento de bairros; (n) Questões Ético-morais aparecem quando as postagens tratam de aborto, religião e corrupção; (o) Esporte corresponde a políticas voltadas à prática do esporte; (p) Cultura considera políticas na área como criação de espaços culturais, verba para programas culturais, revitalização de teatros, etc.; (q) Ações Participativas categorizam textos sobre 
participação popular, orçamento participativo, conselhos, etc.; (r) Variedades engloba as postagens que não dizem respeito nem a temas de políticas públicas nem à campanha eleitoral, tal como eventos sociais e questões da esfera privada. Ou seja, assuntos que não têm vertente política; (s) Conjunto de Políticas trata de textos que não têm um tema específico, mas abordam diversas propostas e assuntos; $(\mathrm{t})$ a categoria "Outro" engloba as entradas que não se enquadram nos temas selecionados previamente.

Também optou-se pela análise das estratégias de discurso, pois acredita-se que isso caracteriza - em parte - a campanha online. Neste caso são 10 possíveis características: (a) agenda de campanha, (b) apoio de líderes/famosos aos candidatos, (c) apoio ao partido, (d) realizações em outras esferas/cargos, (e) proposição de políticas, (f) ataque aos adversários, (g) defesa de ataques realizados, (h) informações externas à campanha, (i) ataque a administração em outras esferas, (j) uso de pesquisa de intenção de voto. Estas estratégias foram analisadas a partir de variáveis dummys, considerando a presença ou ausência de cada uma em determinada postagem.

Observando o discurso juntamente ao temário, pretende-se identificar diferentes formas de uso da internet pelos candidatos e o papel desse meio de comunicação como ferramenta de campanha eleitoral. Os primeiros dados a serem apresentados mostram o mapa com os quais se vai trabalhar, referente aos oito candidatos.

\section{Estratégias e temas de campanha: padrões e usos dos web- sites pelos candidatos em 2012}

A tabela abaixo mostra que Curitiba foi a cidade onde os três principais candidatos alimentaram mais seus sites, totalizando 549 posts, sendo que 44,9\% são provenientes do site do então candidato Gustavo Fruet. Em São Paulo, o total dos três candidatos foi de 366, sendo que Serra foi responsável por $61,74 \%$ dos textos analisados. Muito próximo está o Rio de Janeiro, onde foram analisadas 353 postagens. Comparando em cada disputa, Marcelo Freixo foi o candidato mais ativo no Rio, assim como Serra concentrou mais publicações em São Paulo. Em Curitiba, Fruet e Ducci estiveram mais próximos. Observando os três cenários de disputa, São Paulo é onde há maior divergência entre os 
candidatos no que diz respeito à atuação na rede. O número de postagens indica uma primeira divergência entre os opositores, mostrando que o uso tende a ser diferenciado, principalmente no que diz respeito à "alimentação" diária de conteúdo.

Tabela I - Quantidade de postagens de cada capital e seus candidatos

\begin{tabular}{lccc}
\hline Cidade & Candidato & N & $\%$ \\
\hline \multirow{4}{*}{ Curitiba } & Fruet & 247 & 44,99 \\
& Ducci & 198 & 36,06 \\
& Ratinho Jr. & 104 & 18,94 \\
Rio de Janeiro & Total & 549 & 100 \\
& Paes & 128 & 36,26 \\
& Freixo & 225 & 63,73 \\
São Paulo & Total & 353 & 100 \\
& Haddad & 63 & 17,21 \\
& Serra & 226 & 61,74 \\
& Russomano & 77 & 21,03 \\
\hline Total de postagens & Total & 366 & 100 \\
\hline
\end{tabular}

Fonte:Autoras (2014)

Como discutido anteriormente, acredita-se que a internet seja um novo espaço de campanha onde o candidato pode fornecer informações aos eleitores sem precisar passar pelos filtros dos meios de comunicação e meios tradicionais. Dessa maneira, a comunicação torna-se mais direta e menos influenciada pelas instituições externas (Cunha e Figueiras, 2012). Portanto, cria-se mais um espaço privilegiado aos candidatos - principalmente aqueles que não têm tanto espaço na mídia tradicional, sobretudo no HGPE, onde o tempo não é igualitário e a qualidade dos programas fica condicionada às condições do partido/coligação. Essa primeira informação, embora bastante simples, indica que a rede tem sido usada constantemente durante a campanha, havendo pessoas específicas que fazem as atualizações, o que define as campanhas modernas (Norris, 2002). No entanto, é necessário observar que tipo de comunicação é feita nos websites. Assim como há diferenças quantitativas no uso da rede, acredita-se também que há distinção qualitativa no tipo de uso que é feito deste espaço. 
Por ser um espaço de comunicação direta e com espaço sem restrição, a internet possibilita que os candidatos possam abordar diversas temáticas de maneira mais aprofundada, algo que a campanha na televisão, por meio do HGPE, talvez não viabilize devido ao tempo. Isso significa que se espera que a rede não sirva somente para falar dos fatos inerentes à campanha, mas também sirva para debater temas, como saúde, educação e mobilidade, por exemplo. Esses dados mostram - inclusive - quais temas pautaram cada disputa. Para viabilizar a apresentação desses dados, 10 outras categorias de temas que foram bastante irrisórios na rede foram agrupadas em "outras políticas". Sendo assim, a tabela 2 traz a distribuição dos principais temas identificados na campanha realizada nos websites.

Analisando os dados verifica-se que o tema 'campanha eleitoral' foi predominante em boa parte dos textos postados pelos candidatos a prefeito de Curitiba, Rio de Janeiro e São Paulo, com exceção de Ducci, Paes e Serra, que optaram por diluir os textos em outras temáticas, não concentrando apenas na discussão sobre fatos intrínsecos à campanha, havendo sempre um tema de fundo que norteava o debate. O website de Freixo, por exemplo, tratou em 59,1\% dos textos publicados apenas de fatos da campanha, sem citar nenhum tema de política pública e apresentar um debate mais temático. Ao contrário, Serra tem apenas $16,4 \%$ dos textos sem apresentar relação com algum tema específico. Os percentuais indicam claramente uma concentração do uso da rede para tratar de assuntos factuais da campanha, sem relação com um debate temático. Isso quebra com a ideia de um debate mais temático na rede, como se pensava anteriormente. No entanto, três dos oito candidatos utilizam a rede tendo algum tema de fundo em mais de $40 \%$ dos textos. Ressalta-se que não se tratam de temas necessariamente propositivos, pois isso se trata de uma estratégia que será discutida na sequência. Portanto, é possível identificar ainda que tipo de tema exploram esses candidatos.

Quando se recorre ao teste do qui-quadrado e aos resíduos padronizados, que possibilitam verificar se as relações são estatisticamente significativas entre as categorias das variáveis - neste caso tema e candidatos -, observa-se que os resultados são significativos. Dessa maneira, percebe-se que há temáticas determinadas que tendem a aparecer mais para determinado candidato, diferenciando sua campanha das demais. Acompanhado dos resíduos, é possível notar qual é a categoria que tende a marcar cada campanha iniciando 


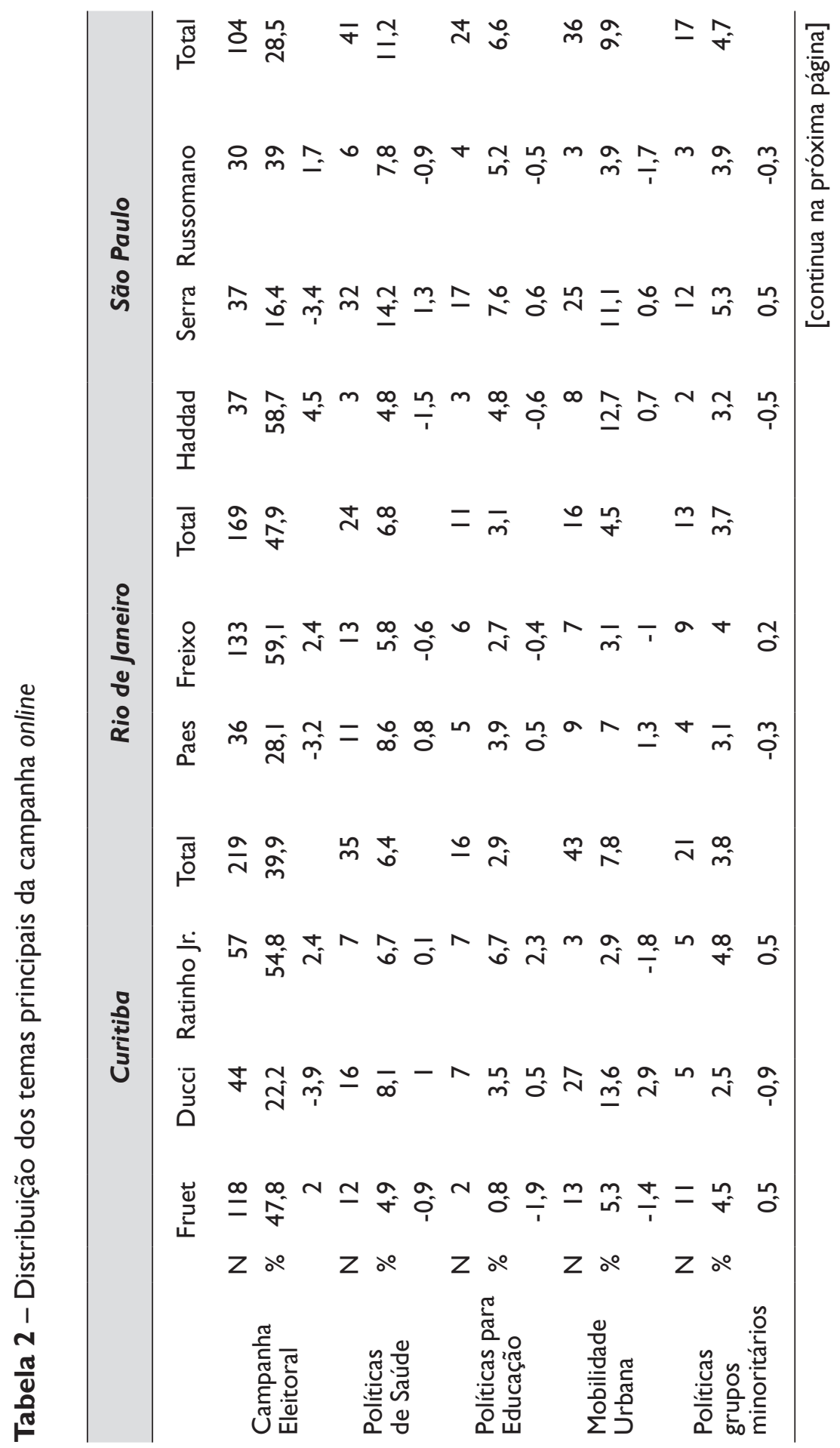




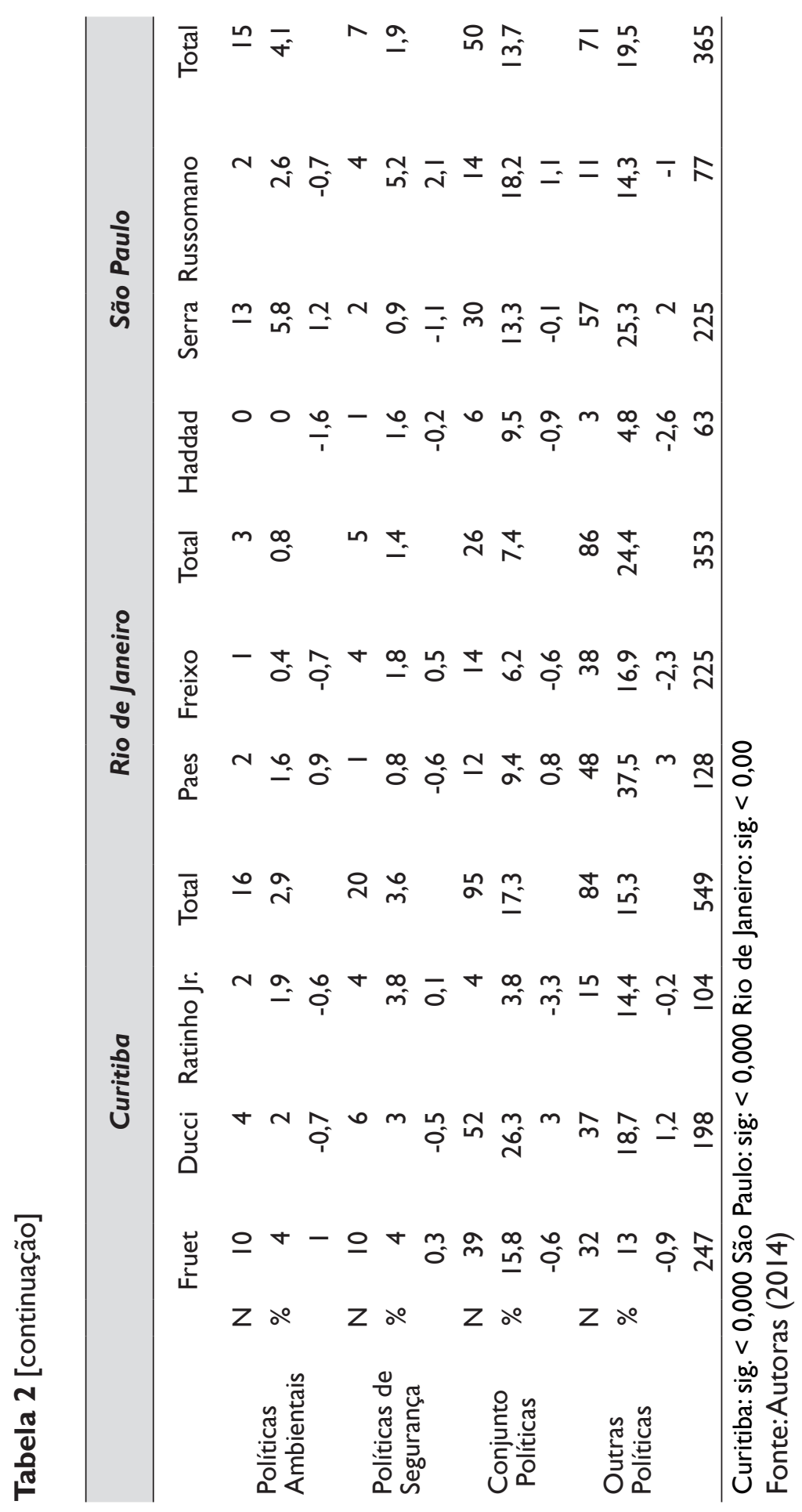


um mapeamento prévio do tipo de perfil e uso da rede por parte de cada um.

Os resíduos padronizados presentes na tabela nos permitem medir a força da relação entre as categorias da variável "tema" e nos mostram onde as relações são mais significativas. Quanto maior o resíduo $( \pm 1,96)$, mais forte é a relação, seja de proximidade ou distanciamento entre as categorias. Dessa maneira, o teste indica que em Curitiba o conteúdo dos textos de Ratinho Jr. foi o que mais teve tendência a tratar sobre a temática campanha eleitoral $(2,4)$ e políticas para educação $(2,3)$, ao passo de que esteve mais distante de apresentar textos abordando um conjunto de políticas $(-3,3)$, ou seja, textos que falam de vários assuntos relacionados. Em contrapartida, o candidato que mais se distanciou do tema campanha eleitoral foi Luciano Ducci $(-3,9)$, que preferiu priorizar a temática mobilidade urbana $(2,9)$ e conjunto de políticas (3). Uma possível explicação para isso é que o então candidato concorria à reeleição e já detinha conhecimentos administrativos e técnicos para tratar de questões mais pontuais. Mais à frente será possível notar que o candidato enfatizava suas ações na administração e, com isso, envolvia certos temas. Por fim, a campanha online de Fruet apresenta aproximação com a temática campanha (2) e se distancia de políticas para educação.

No Rio de Janeiro, Eduardo Paes manteve-se mais distante do tema campanha $(-3,2)$, enquanto que os textos de Freixo tiveram tendência de aproximação $(2,4)$, de acordo com o teste. Ou seja, neste cenário Freixo abordou mais fatos inerentes à campanha apenas. Enquanto isso, tratou mais de outras políticas, ou seja, das categorias agrupadas, como foi explicado anteriormente, mas sem ter um tema central da sua campanha, como foi possível perceber na campanha de Curitiba. Embora existisse um tema de fundo, ele era sempre muito difuso, variando em cada publicação. No entanto, da mesma maneira que Ducci, candidato à reeleição, tinha mais proximidade com temáticas, talvez por também enfatizá-las ao reforçar suas políticas.

Em São Paulo, Fernando Haddad apresenta a relação mais forte entre candidato e tema campanha eleitoral $(4,5)$, inclusive das três cidades analisadas neste artigo. Já a campanha de Serra optou por se afastar desse tema, priorizando, por exemplo, outras políticas e, do mesmo modo que Paes, não teve um tema que 
marcasse sua campanha na rede, diferenciando-se dos demais candidatos. Pelos resultados da tabela, identifica-se novamente com o caso de Serra que os candidatos à reeleição ou da situação não priorizaram conteúdo referente à campanha eleitoral, sendo mais temáticos em suas publicações, enquanto que os desafiantes procuraram falar mais especificamente de fatos inerentes à campanha. Russomano foca a campanha em questões de segurança $(2,1)$.

Por fim, esses dados indicam quatro pontos: (a) textos focados em campanha representam mais de $40 \%$ das postagens para cinco candidatos, o que leva a crer que mesmo com a potencialidade, a rede é menos usada para debate temático; (b) candidato à reeleição ou que já ocupou cargo no executivo tende a ser menos focado em fenômenos inerentes à campanha, abordando mais temas para respaldar a campanha, principalmente porque ressaltam suas ações passadas em determinados setores; (c) os candidatos tendem a ter um tema específico que marca a campanha, com exceção de Fruet, Paes e Serra, que embora tratem de temas, não há um que se sobressaia sobre os demais. (d) tema já é um quesito que diferencia candidatos, inclusive mesmo de uma mesma disputa, contribuindo para reafirmar as hipóteses da pesquisa.

O próximo quesito a ser analisado são as estratégias de discurso utilizadas pelos candidatos. Na pesquisa são 10 estratégias, embora aqui apresentemos somente sete delas, por serem as mais significantes. A primeira estratégia analisada é o uso da agenda dos candidatos na campanha nos sites. A relação entre uso da agenda e candidato se mostra significativa para os candidatos de Curitiba e Rio de Janeiro, com coeficientes elevados, mas não para São Paulo ${ }^{5}$. Vejamos os resultados apresentados pela tabela 3:

5. A partir da tabela 3 , onde se pretende comparar os candidatos dentro de cada cenário eleitoral e entre os demais, utilizam-se os valores dos coeficientes, mesmo que a pesquisa trabalhe com o número total de entradas ao longo do período. O objetivo é verificar onde estão as relações e diferenças mais significativas por meio da comparação dos coeficientes. 
Tabela 3 - Uso de agenda na campanha online

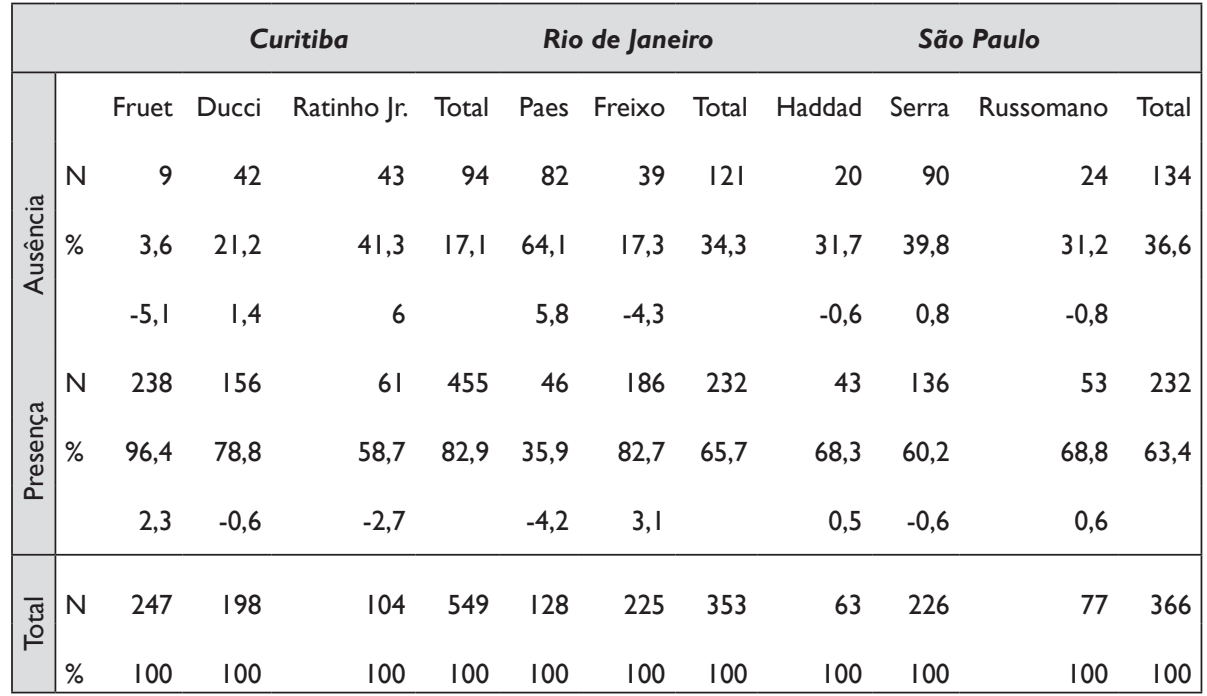

qui-quadrado: Curitiba:76,962 Rio de Janeiro: 79,08। São Paulo: 2,630

Fonte:Autoras (2014)

Outra estratégia, também recorrente em outras esferas de campanha e transportada para a internet é a presença de apoio ao candidato, manifestado geralmente por outros políticos ou pessoas expressivas no contexto social e político. $\mathrm{Na}$ internet, mais especificamente nos sites dos candidatos, verifica-se que a utilização dessa estratégia também não é consenso.

Eduardo Paes foi o que mais explorou esse recurso, presente em $46,1 \%$ do total do conteúdo. Os resíduos padronizados também demonstram a forte relação entre o candidato e a presença dessa estratégia (6). Em São Paulo, a presença do apoio também é verificada em uma parte do conteúdo postado no site de Haddad (23,8\%), porém, em menor intensidade $(4,3)$.

Esses dados revelam que a campanha tomou rumos diferentes nos três cenários estudados. Enquanto em Curitiba os três aspirantes ao cargo, majoritariamente, não trouxeram muitos apoios para a campanha online, no Rio e em São Paulo verifica-se uma mudança de estratégia. Em Curitiba, os poucos apoios vieram de deputados e da ex-ministra da Casa Civil. Em São Paulo, Haddad contava com o apoio, também de cunho político, de deputados e principalmente da presidente Dilma Rousseff. Até aqui a estratégia foi receber apoio de outros políticos para ajudar a construção da 
imagem, pois essas pessoas falavam com o objetivo de construir a imagem dos novos candidatos (Albuquerque, 1999). Vale destacar que no caso de Eduardo Paes, candidato à reeleição, o apoio vinha de pessoas famosas que são cariocas e que ressaltavam as melhorias trazidas por Paes, destacando seu voto pela continuidade, ou seja, são funções diferentes de uma mesma estratégia: para formar a imagem dos candidatos e para respaldar ações já realizadas. De todo modo, trata-se de uma estratégia personalista voltada para enfatizar o candidato. A variável para pedir apoio ao partido teve números irrisórios.

Tabela 4 - Presença de Apoio ao candidato

\begin{tabular}{|c|c|c|c|c|c|c|c|c|c|c|c|c|}
\hline & & \multicolumn{4}{|c|}{ Curitiba } & \multicolumn{3}{|c|}{ Rio de Janeiro } & \multicolumn{4}{|c|}{ São Paulo } \\
\hline \multirow{4}{*}{ 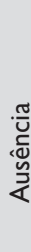 } & & Fruet & Ducci & Ratinho Jr. & Total & Paes & Freixo & Total & Haddad & Serra & Russomano & Total \\
\hline & $N$ & 226 & 190 & 101 & 517 & 69 & 208 & 277 & 48 & 214 & 74 & 336 \\
\hline & $\%$ & 91,5 & 96 & 97,1 & 94,2 & 53,9 & 92,4 & 78,5 & 76,2 & 94,7 & 96,1 & 91,8 \\
\hline & & $-0,4$ & 0,3 & 0,3 & & $-3,1$ & 2,4 & & $-1,3$ & 0,5 & 0,4 & \\
\hline \multirow{3}{*}{ 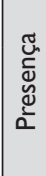 } & $\mathrm{N}$ & 21 & 8 & 3 & 32 & 59 & 17 & 76 & 15 & 12 & 3 & 30 \\
\hline & $\%$ & 8,5 & 4 & 2,9 & 5,8 & 46,1 & 7,6 & 21,5 & 23,8 & 5,3 & 3,9 & 8,2 \\
\hline & & I,7 & -1 & $-1,2$ & & 6 & $-4,5$ & & 4,3 & $-1,5$ & $-1,3$ & \\
\hline \multirow{2}{*}{$\begin{array}{l}\text { त्ञّ } \\
0\end{array}$} & $N$ & 247 & 198 & 104 & 549 & 128 & 225 & 353 & 63 & 226 & 77 & 366 \\
\hline & $\%$ & 100 & 100 & 100 & 100 & 100 & 100 & 100 & 100 & 100 & 100 & 100 \\
\hline
\end{tabular}

qui-quadrado: Curitiba: 6,012 Rio de Janeiro: 71,723 São Paulo: 24,804 Fonte:Autoras (2014)

Desqualificar o adversário durante a campanha eleitoral é outra estratégia que pode ser adotada pelos candidatos. Mas será que essa é uma das finalidades da campanha online? A resposta é que depende do candidato, conforme mostram os dados a seguir. Dentre todos os candidatos, o uso do ataque foi mais identificado na campanha de Haddad (23,8\%), seguido por Celso Russomano $(10,4 \%)$ e Serra $(5,8 \%)$. Dos três cenários analisados apenas em São Paulo, o ataque ao candidato adversário é uma estratégia que define determinadas campanhas na rede, como mostra o teste de significância e os resíduos padronizados positivos. 
Tabela 5 - Ataque aos opositores

\begin{tabular}{|c|c|c|c|c|c|c|c|c|c|c|c|c|}
\hline & & & & Iritiba & & & de Jane & & & Sãc & Paulo & \\
\hline & & Fruet & Ducci & Ratinho Jr. & Total & Paes & Freixo & Total & Haddad & Serra & Russomano & Total \\
\hline$\underline{. \Xi}$ & $N$ & 239 & 192 & 102 & 533 & 128 & 215 & 343 & 48 & 213 & 69 & 330 \\
\hline 矛 & $\%$ & 96,8 & 97 & 98,1 & 97,1 & 100 & 95,6 & 97,2 & 76,2 & 94,2 & 89,6 & 90,2 \\
\hline 4 & & $-0,1$ & 0 & 0,1 & & 0,3 & $-0,2$ & & $-1,2$ & 0,6 & $-0,1$ & \\
\hline$\pi$ & $N$ & N 8 & 6 & 2 & 16 & 0 & 10 & 10 & 15 & 13 & 8 & 36 \\
\hline$\overline{\bar{y}}$ & $\%$ & 3,2 & 3 & 1,9 & 2,9 & 0 & 4,4 & 2,8 & 23,8 & 5,8 & 10,4 & 9,8 \\
\hline$a$ & & 0,3 & 0,1 & $-0,6$ & & $-1,9$ & I,4 & & 3,5 & -2 & 0,2 & \\
\hline $\bar{\Xi}$ & $\mathrm{N}$ & 247 & 198 & 104 & 549 & 128 & 225 & 353 & 63 & 226 & 77 & 366 \\
\hline & $\%$ & 100 & 100 & 100 & 100 & 100 & 100 & 100 & 100 & 100 & 100 & 100 \\
\hline
\end{tabular}

qui-quadrado: Curitiba: 0,463 Rio de Janeiro: 5,855 São Paulo: 18,147

Fonte:Autoras (2014)

Os resíduos nos indicam que há relação positiva apenas entre Haddad e a presença de ataque aos adversários $(3,5)$, sendo que neste caso foi tanto para criticar Serra quanto Russomanno. Uma possível explicação para isso é o fato, mais uma vez, de Haddad ser de oposição, ter começado a campanha com baixo percentual nas pesquisas de intenção de voto e precisar ganhar espaço na preferência dos eleitores, principalmente por não ser, até então, extremamente conhecido - diferentemente de Serra, que já havia sido governador, e Russomano, um dos apresentadores de maior visibilidade da capital paulista. A estratégia de desestabilizar e desqualificar os adversários foi, de modo geral, pouco usada nos três cenários analisados na rede, apenas ressaltando sua presença na campanha de Haddad. Os candidatos de Curitiba e Rio de Janeiro se mantiveram neutros nesse sentido, destacando-se o posicionamento da campanha de Paes, onde não foi identificado nenhum caso de ataque ao opositor durante o primeiro turno, inclusive porque Paes era um candidato bem colocado nas pesquisas, não necessitando desqualificar os adversários para angariar votos. Em Curitiba, apesar da disputa acirrada e do esperado uso da campanha negativa, ela foi pouco frequente nos websites, padronizando a ausência entre os candidatos. Talvez ela pudesse, por exemplo, aparecer no rádio, como constatou Borba (2012) e não na internet, mas isso depende da estratégia geral da campanha. 
A próxima variável diz respeito ao ataque realizado à administração vigente do período. Pressupõe a forte utilização dessa variável pelos candidatos de oposição, principalmente para desqualificar os candidatos à reeleição. Obviamente não é uma estratégia que vai aparecer em todos os perfis de candidatos. Inclusive na campanha nos websites, onde se esperava maior presença da campanha negativa, apenas Fruet e Freixo tem números significativos positivos.

Tabela 6 - Ataque à administração em curso

\begin{tabular}{|c|c|c|c|c|c|c|c|c|c|c|c|c|}
\hline & & & & ritiba & & & de Jan & & & São & Paulo & \\
\hline & & Fruet & Ducci & Ratinho Jr. & Total & Paes & Freixo & Total & Haddad & Serra & Russomano & Total \\
\hline & $N$ & 194 & 198 & 103 & 495 & 127 & 191 & 318 & 60 & 209 & 66 & 335 \\
\hline 莺 & $\%$ & 78,5 & 100 & 99 & 90,2 & 99,2 & 84,9 & 90,1 & 95,2 & 92,5 & 85,7 & 91,5 \\
\hline$<$ & & $-1,9$ & I,5 & I & & I,I & $-0,8$ & & 0,3 & 0,1 & $-0,5$ & \\
\hline (ז) & $\mathrm{N}$ & 53 & 0 & 1 & 54 & I & 34 & 35 & 3 & 17 & II & 31 \\
\hline \begin{tabular}{l|l}
$\bar{\Phi}$ \\
$\Phi$ \\
$\Phi$
\end{tabular} & $\%$ & 21,5 & 0 & I & 9,8 & 0,8 & $15, \mid$ & 9,9 & 4,8 & 7,5 & 14,3 & 8,5 \\
\hline & & 5,8 & $-4,4$ & $-2,9$ & & $-3,3$ & 2,5 & & -1 & $-0,5$ & 1,8 & \\
\hline$\overline{\mathrm{J}}$ & $\mathrm{N}$ & 247 & 198 & 104 & 549 & 128 & 225 & 353 & 63 & 226 & 77 & 366 \\
\hline & $\%$ & 100 & 100 & 100 & 100 & 100 & 100 & 100 & 100 & 100 & 100 & 100 \\
\hline
\end{tabular}

qui-quadrado: Curitiba: 68,45। Rio de Janeiro:8,757 São Paulo: 4,739

Fonte:Autoras (2014)

Olhando apenas para o percentual, dentre as três cidades, o candidato que mais atacou a administração foi Gustavo Fruet, em Curitiba, em 21,5\% dos posts. Marcelo Freixo adotou a estratégia em 15,1\% e Russomano, em São Paulo, apresentou essa estratégia em $14,3 \%$ do material da campanha online no primeiro turno. No entanto, a relação é significativa apenas para Curitiba e São Paulo. Há forte relação entre a presença dessa estratégia na campanha de Fruet $(5,8)$ e Freixo $(2,5)$. Por motivos óbvios, os candidatos à reeleição não criticaram nenhum aspecto da gestão e procuraram se afastar dessa estratégia, como é o caso de Ducci $(-4,4)$ e Paes $(-3,3)$. $\mathrm{O}$ ataque, que caberia aos oponentes, foi explorado, mas não foi o foco estratégico da campanha online de todos os candidatos das três cidades. Ratinho Jr não usou a ferramenta. No caso de São Paulo, destaca-se que Serra se referia de maneira negativa a ex-prefeitos 
petistas em gestões anteriores. Já Russomano e Haddad, no pouco que usaram, criticaram a gestão de Gilberto Kassab. No entanto, o uso foi muito similar entre eles, o que não gera distinções e resíduos, além de pouco presente. Ou seja, aqui o padrão demonstra ausência da estratégia para todos os candidatos.

Se os candidatos da situação se esquivaram de reconhecer possíveis problemas de gestão naquele momento, reforçaram as atuações em outras esferas, ou seja, em outros cargos ou instâncias. Essa é uma estratégia típica de mandatário, mas exige que o candidato tenha histórico político. Ou seja, a variável que explica a presença dessa característica é sua trajetória política. A tabela 7 apresenta esses dados, que são significativos para todos os cenários.

Tabela 7 - Realização em outras esferas

\begin{tabular}{|c|c|c|c|c|c|c|c|c|c|c|c|c|}
\hline & & & & itiba & & & de Jan & & & São & Paulo & \\
\hline & & Fruet & Ducci & Ratinho Jr. & Total & Paes & Freixo & Total & Haddad & Serra & Russomano & Total \\
\hline & $\mathrm{N}$ & 226 & 55 & 88 & 369 & 56 & 215 & $27 \mid$ & 57 & 87 & 72 & 216 \\
\hline 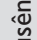 & $\%$ & 91,5 & 27,8 & 91,7 & 68,2 & 43,8 & 95,6 & 76,8 & 90,5 & 38,5 & 93,5 & 59 \\
\hline & & 4,4 & $-6,9$ & 2,8 & & $-4,3$ & 3,2 & & 3,3 & -4 & 3,9 & \\
\hline & $\mathrm{N}$ & 21 & 143 & 8 & 172 & 72 & 10 & 82 & 6 & 139 & 5 & 150 \\
\hline$\overline{\bar{\nu}}$ & $\%$ & 8,5 & 72,2 & 8,3 & 31,8 & 56,3 & 4,4 & 23,2 & 9,5 & 61,5 & 6,5 & 41 \\
\hline & & $-6,5$ & 10,1 & $-4,1$ & & 7,8 & $-5,8$ & & $-3,9$ & 4,8 & $-4,7$ & \\
\hline $\bar{J}$ & $\mathrm{~N}$ & 247 & 198 & 96 & $54 I$ & 128 & 225 & 353 & 63 & 226 & 77 & 366 \\
\hline & $\%$ & 100 & 100 & 100 & 100 & 100 & 100 & 100 & 100 & 100 & 100 & 100 \\
\hline
\end{tabular}

qui-quadrado: Curitiba: 235,397 Rio de Janeiro: 122,783 São Paulo: 102,997

Fonte:Autoras (2014)

Todos os candidatos que já ocuparam cargos no executivo - Ducci, Paes e Serra - se utilizaram dessa estratégia. Esse é um padrão de campanha na rede, por exemplo. Não é algo típico de desafiantes e esperava-se justamente que os três fizessem uso da rede para enfatizar sua carreira política. Em Curitiba, o então prefeito Luciano Ducci utilizou a estratégia de explorar suas atuações em outra esfera - como no cargo de vice-prefeito, ocupado até a saída de Beto Richa (PSDB) para concorrer ao governo do estado - em mais de $70 \%$ das 
postagens do seu site pessoal. Entre os três candidatos da situação, ele foi o que mais recorreu às realizações passadas e o que possui a relação mais forte de proximidade com a presença dessa estratégia $(10,1)$. Em São Paulo, José Serra também utilizou da sua trajetória política para defender a candidatura em $61,5 \%$ do conteúdo. O candidato pelo PSDB à prefeitura de São Paulo apresenta ligação com a estratégia, embora em menor intensidade que Ducci. Dentre os concorrentes à reeleição - ou que representam a situação -, Eduardo Paes foi o que menos empregou a estratégia, apesar de ela estar presente em mais de $56 \%$ da sua campanha online e o candidato estar fortemente alinhado com a presença desse recurso, conforme indica o resíduo padronizado $(7,8)$. Ressalta-se que não significa que essa estratégia não possa aparecer para outros candidatos; no entanto, por serem cargos no legislativo ou em ministério, por exemplo, a referência torna-se menos expressiva. Contudo, isso muda quando o candidato é da situação, onde ele pode recuperar suas realizações a título, talvez, de prestar contas também.

Algo que é acompanhado e explorado eventualmente pelos candidatos são as pesquisas de opinião pública, por isso considera-se como uma estratégia relacionada à formação da imagem perante os eleitores. Elas são parâmetros de comparação entre a preferência do público por determinado candidato e um termômetro para a campanha em si. Se o candidato vai mal nas pesquisas, as estratégias de campanha podem mudar, visando capturar a atenção e preferência dos eleitores. Por outro lado, quando os candidatos estão bem posicionados, podem utilizar os resultados para enfatizar a própria imagem por meio do marketing político. Ressalta-se que, da mesma forma que outras estratégias, a explicação para sua presença está no cenário de disputa e na posição ocupada pelo candidato. Ou seja, apenas candidatos bem posicionados usam essa estratégia para reforçar sua imagem. Poucos casos mostram candidatos em segundo ou terceiro lugar usando a estratégia, no máximo para enfatizar que a posição está melhorando. Sendo assim, espera-se que apenas Ratinho Jr, Paes e Russomano utilizem com ênfase tal estratégia. No entanto, como mostram os dados, essa não foi uma estratégia usada por Paes e sua assessoria, embora ele estivesse sempre muito acima do segundo colocado, Freixo. Além disso, de modo geral ela foi pouco usada, mesmo havendo cenário propício. 
Tabela 8 - Uso de pesquisa de Opinião Pública

\begin{tabular}{|c|c|c|c|c|c|c|c|c|c|c|c|c|}
\hline & & \multicolumn{4}{|c|}{ Curitiba } & \multicolumn{3}{|c|}{ Rio de Janeiro } & \multicolumn{4}{|c|}{ São Paulo } \\
\hline & & Fruet & Ducci & Ratinho Jr. & Total & Paes & Freixo & Total & Haddad & Serra & Russomano & Total \\
\hline \multirow{3}{*}{ 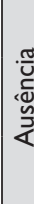 } & $N$ & N 245 & 194 & 94 & 533 & 128 & 220 & 348 & 60 & 223 & 70 & 353 \\
\hline & $\%$ & $\% 99,2$ & 98 & 90,4 & 97,1 & 100 & 97,8 & 98,6 & 95,2 & 98,7 & 90,9 & 96,4 \\
\hline & & 0,3 & 0,1 & $-0,7$ & & 0,2 & $-0,1$ & & $-0,1$ & 0,3 & $-0,5$ & \\
\hline \multirow{3}{*}{ 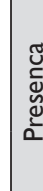 } & $N$ & N 2 & 4 & 10 & 16 & 0 & 5 & 5 & 3 & 3 & 7 & 13 \\
\hline & $\%$ & $\% 0,8$ & 2 & 9,6 & 2,9 & 0 & 2,2 & I,4 & 4,8 & 1,3 & 9,1 & 3,6 \\
\hline & & $-1,9$ & $-0,7$ & 4 & & $-1,3$ & I & & 0,5 & $-1,8$ & 2,6 & \\
\hline \multirow{2}{*}{$\mid \begin{array}{l}\bar{\Xi} \\
\stackrel{0}{0}\end{array}$} & N & N 247 & 198 & 104 & 549 & 128 & 225 & 353 & 63 & 226 & 77 & 366 \\
\hline & $\%$ & $\% 100$ & 100 & 100 & 100 & 100 & 100 & 100 & 100 & 100 & 100 & 100 \\
\hline
\end{tabular}

qui-quadrado: Curitiba: 20,93। Rio de Janeiro: 2,885 São Paulo: 10,430

Fonte:Autoras (2014)

A presença da pesquisa de opinião pública foi identificada com certa significância em duas campanhas: na de Ratinho Jr, em Curitiba, e na de Russomano, em São Paulo. O teste de resíduos mostra que o conteúdo dos dois candidatos está fortemente relacionado com a presença dessa estratégia. Os demais candidatos quase não trataram de pesquisa de opinião na campanha online, apenas em casos residuais para reforçar a melhora nos números. Vale lembrar que Ratinho Jr. e Russomano lideravam as pesquisas, apesar do cenário ter se invertido ao longo dos meses e ambos ficarem de fora do $2^{\circ}$ turno. Isso é que explica esses resultados encontrados. O que difere é Paes não ter feito o uso da estratégia, já que o cenário estava ao seu favor.

Por fim, apresentam-se os resultados sobre a campanha propositiva na rede, ou seja, se houve discussão de temas de interesse público, estratégia que não tem sido identificada como principal foco dos candidatos, cedendo espaço à formação da imagem pública, principalmente no HGPE, conforme apontam alguns estudos, entre eles o de Cervi e Massuchin (2010). A proposta é principalmente entender se a internet - um novo espaço que compõe as campanhas 
- tem sido usada para o debate temático em contraposição à ideia de que a rede seja usada apenas para transposição do conteúdo offline. Como a internet é uma plataforma que não limita espaço, os candidatos têm a possibilidade de fazer mais discussões propositivas ao invés de dedicarem todo o conteúdo para construir sua imagem para o público ou fazerem referência apenas ao cotidiano de campanha. Como já foi dito, as estratégias não são excludentes. Portanto, a proposição de temas pode estar relacionada com outras estratégias e até mesmo estar junto com a agenda de campanha, já que muitos candidatos utilizam a agenda para um gancho do debate temático posterior, mostrando e enfatizando suas propostas. Espera-se que ela apareça, de maneira geral entre os candidatos, como uma marca da campanha na rede, podendo ser comparado com a presença de agenda de campanha. No entanto, claro, há chances de alguns candidatos serem mais propositivos que outros. A tabela 9 mostra que, de fato, a discussão propositiva perpassou a campanha dos principais candidatos das três cidades, mas com algumas diferenças entre os candidatos de cada cenário.

$\mathrm{Na}$ campanha curitibana, Fruet apresentou discussões propositivas em praticamente metade do conteúdo veiculado em seu site, enquanto Ducci enfocou nessa estratégia em $55 \%$ dos posts. Ratinho Jr. também abordou temas de interesse público em 39,4\% da sua campanha. Em São Paulo, o candidato Russomano se destacou no uso dessa estratégia - $61 \%$ dos textos apresentaram algum tipo de debate propositivo. Serra apresentou percentual próximo ao de Ducci, debatendo proposições de políticas públicas em mais de $53 \%$ do conteúdo gerado em seu site. Haddad foi o candidato paulista que menos priorizou a estratégia (38,1\%). Já no Rio de Janeiro, a campanha online foi a menos propositiva, em vista das demais cidades. Apesar de ter sido identificada, Paes e Freixo optaram por outros enfoques, visto que a apresentação de temas de interesse público foi verificada em apenas $14,1 \%$ do conteúdo eleitoral de Eduardo Paes e de 34,7\% de Marcelo Freixo. Em relação ao cenário do Rio, Freixo se destaca aproximando seu debate online da proposição de políticas, o que caracterizou sua campanha de oposição. Já Paes, apesar de não usar a rede para transpor a campanha offline, também não propõe debate. 
Tabela 9 - Uso de campanha propositiva na rede

\begin{tabular}{|c|c|c|c|c|c|c|c|c|c|c|c|c|}
\hline & & & & ritiba & & & de Jan & & & São & Paulo & \\
\hline & & Fruet & Ducci & Ratinho Jr. & Total & Paes & Freixo & Total & Haddad & Serra & Russomano & Total \\
\hline & $\mathrm{N}$ & 125 & 89 & 63 & 277 & 110 & 147 & 257 & 39 & 105 & 30 & 174 \\
\hline 矛 & $\%$ & 50,6 & 44,9 & 60,6 & 50,5 & 85,9 & 65,3 & 72,8 & 61,9 & 46,5 & 39 & 47,5 \\
\hline$\ll$ & & 0 & $-I, I$ & I,5 & & I,7 & $-1,3$ & & I,7 & $-0,2$ & $-I, I$ & \\
\hline & $\mathrm{N}$ & 122 & 109 & 41 & 272 & 18 & 78 & 96 & 24 & 121 & 47 & 192 \\
\hline एँ & $\%$ & 49,4 & $55, I$ & 39,4 & 49,5 & $|4|$, & 34,7 & 27,2 & 38,1 & 53,5 & 61 & 52,5 \\
\hline$a$ & & 0 & $\mathrm{I}, \mathrm{I}$ & $-1,5$ & & $-2,8$ & 2,1 & & $-1,6$ & 0,2 & I & \\
\hline$\sqrt{3}$ & $\mathrm{~N}$ & 247 & 198 & 104 & 549 & 128 & 225 & 353 & 63 & 226 & 77 & 366 \\
\hline & $\%$ & 100 & 100 & 100 & 100 & 100 & 100 & 100 & 100 & 100 & 100 & 100 \\
\hline
\end{tabular}

qui-quadrado: Curitiba: 6,666 Rio de Janeiro: 17,493 São Paulo: 7,59I

Fonte:Autoras (2014)

De modo geral, após o uso da rede para transpor a campanha, esse mesmo espaço é utilizado para debater propostas de políticas públicas, com exceção dos candidatos que fizeram o uso exacerbado da ênfase em realizações (Ducci, Paes e Serra). De toda forma, está entre as estratégias mais utilizadas. Portanto, é possível dizer que a rede não é apenas usada para transpor a campanha offline, mas ela também serve para ampliar o debate, sendo um espaço importante para a proposição de temas de políticas. A fim de colaborar com a melhor visualização do uso que os candidatos fazem das estratégias apresentadas acima, o gráfico a seguir traz a representação desses resultados.

Com o gráfico, visualizam-se melhor as estratégias mais empregadas ou não pelos candidatos das três cidades. Candidatos - mesmo de um mesmo cenário - usam seus websites com diferentes funções. Fruet se distingue dos demais por enfatizar o ataque à administração e faz alto uso dos websites para transpor a campanha online. Ducci tende a enfatizar suas realizações passadas, do mesmo modo que Ratinho Jr se destaca por tratar de pesquisas de opinião. Paes, assim como Ducci, enfatiza suas realizações e, além disso, destaca o apoio que recebe nas eleições. Freixo também faz ataques, mas apresenta mais agenda de campanha que os demais na rede. Haddad usa a rede para proferir ataques aos opositores e também ressalta o apoio político que recebe como candidato. Serra se destaca por 
Gráfico I - Distribuição dos resíduos da presença das estratégias

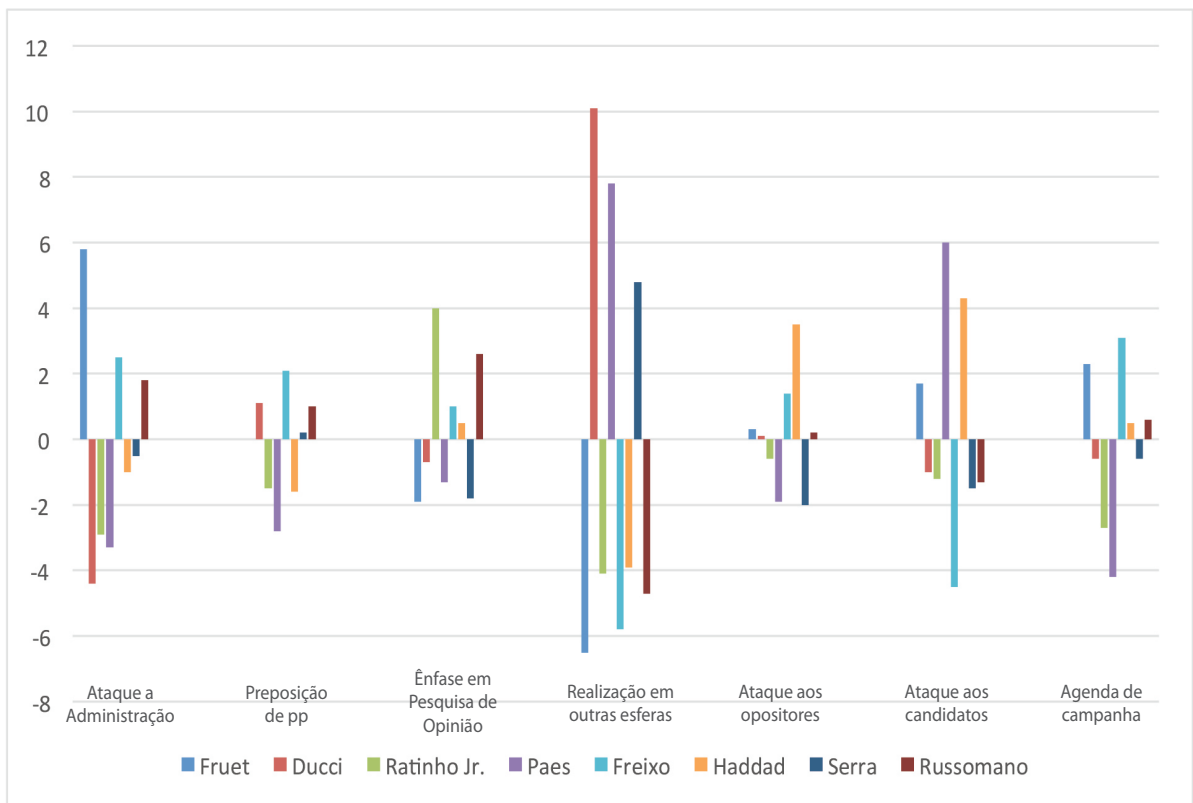

Fonte:Autoras (2014)

enfatizar realizações passadas, assim como Russomanno enfatiza pesquisas de opinião.

Em termos de aproximação, Freixo tende a fazer uma campanha mais semelhante a Fruet, enquanto Paes, Ducci e Serra estão próximos em outra ponta. Russomano e Ratinho Jr também tem algum ponto em comum pela posição que ocupam e suas estratégias. Mais distante está Haddad. Essa proximidade é explicada também pela relação entre suas trajetórias e posições políticas.

\section{Considerações finais}

Este artigo buscou discutir como os principais candidatos ao pleito de São Paulo, Curitiba e Rio de Janeiro utilizaram seus websites no que diz respeito à tematização e estratégias. Ao todo, foi analisado um universo de 1268 textos informativos de campanha postados na aba 'notícias'. A pesquisa partiu das seguintes hipóteses: 1) os candidatos - inclusive do mesmo cenário de disputa - agem de maneira distinta na campanha na internet; 2) embora a internet seja considerada um espaço de transposição das campanhas realizadas 
em outras esferas, também tem a função de ser propositiva. Ambas foram confirmadas pelos dados apresentados aqui.

Sobre os dados analisados, a primeira diferença encontrada é no uso cotidiano feito desse espaço de campanha nos três meses, mesmo se tratando de um mesmo cenário. Enquanto Fruet (PDT) teve 247 postagens, Ratinho Junior (PSC) fez 104, por exemplo. Essas diferenças também aparecem em outros dois cenários políticos analisados, mostrando um primeiro diferencial entre as campanhas.

Sobre a abordagem temática de fundo das postagens, textos focados somente em campanha representam mais de $40 \%$ das postagens para cinco candidatos. Além disso, sobre os textos com abordagem temática, percebe-se que o candidato à reeleição ou que já ocupou cargo no executivo tende a ser menos focado em fenômenos inerentes à campanha, abordando mais temas para respaldar suas ações passadas. A tematização também distingue as campanhas, assim como as estratégias, pois os candidatos tendem a ter um tema específico que marca a campanha, com exceção de Fruet, Paes e Serra, que embora tratem de temas, não há um que se sobressaia sobre os demais. Essa informação vai ao encontro da hipótese inicial em que se afirmava que os candidatos têm perfis diferentes na internet.

No que diz respeito à análise das estratégias, os primeiros resultados indicam que, na internet, duas estratégias se sobressaem para quase todos os candidatos: agenda de campanha e proposição de políticas públicas, ao observar os percentuais altos para presença em ambas as estratégias. Portanto, a rede pode ser considerada um espaço propositivo, e não apenas de transposição da agenda, confirmando a segunda hipótese da pesquisa, em que esperava-se tal resultado para o uso dos websites. Embora saibamos que os diferentes espaços seguem a mesma lógica de campanha e a TV está inserida no online, assim como o cotidiano, esperava-se que a rede atendesse mais aos eleitores já interessados por política, permitindo um debate mais qualitativo e voltado para temas.

No entanto, mesmo observando que os percentuais dessas estratégias aparecem em grande quantidade em relação aos demais, há diferenças entre os candidatos em praticamente todos os cenários e estratégias, o que vai ao encontro também da outra hipótese inicial em que se defendia a rede como um espaço amplo, com diferentes funções. Os temas já são diferentes, como foi possível constatar, sendo que agora também percebeu-se diferença no campo das estratégias 
dos discursos. Há poucos padrões - tanto no discurso quanto no tema - num mesmo cenário. Na maioria dos casos há determinados candidatos que se sobressaem no uso de alguma estratégia, tornando-a praticamente como sua marca de campanha na rede. É o caso, por exemplo, de Paes, que usou a rede para mostrar os apoios que recebia durante o período. Ou Haddad que, diferente dos demais, usou para fazer campanha negativa.

Esses resultados, apesar de não serem retomados aqui na sua totalidade, são explicados em grande maioria pela posição que o candidato ocupa durante o pleito, se é representante da situação, se ocupou alguma posição de destaque em algum governo ou ainda se é oposição. Isso tudo influencia em algumas estratégias e, algumas vezes, aproximam os candidatos de diferentes cenários, como é o caso da apresentação das realizações conquistadas em outras esferas, exploradas por Ducci, Paes e Serra. Ou seja, as aproximações não se dão num mesmo cenário, mas sim pelas características entre os candidatos, sejam eles de uma mesma disputa ou não. Padrões externos moldam padrões internos da rede. Os resultados apresentados aqui dizem respeito apenas aos casos analisados, não permitindo generalizações, mas já indicam determinados recursos que são usados de forma diferente pelos candidatos.

Por fim, consideram-se os websites como um novo espaço de campanha em que os candidatos utilizam determinadas estratégias de discurso, principalmente servindo para transpor a campanha que ocorre em outras esferas e também para propor temas. De resto, como se pode perceber, há diferentes perfis de uso, o que torna a rede um espaço com pouco padrão de uso, tendo diferentes perfis de utilização durante o período que antecede a campanha. Ou seja, embora com algumas aproximações, cada candidato tem uma marca distinta na campanha online. Essa pluralidade de uso torna a internet um espaço com as mais variadas funções, embora importantes dentro da disputa. Essa amplitude pode ser explicada pela novidade que a ferramenta ainda representa, mas também porque não é a rede que molda e define as estratégias, mas sim os candidatos que vem do mundo offline para ocupar esse espaço. Portanto, se os candidatos são diferentes, utilizarão estratégias diferentes, seguindo a lógica dos estudos sobre estratégias eleitorais que são aplicados para a televisão, por exemplo. Com o tempo e com as definições da ferramenta, possivelmente podem ser criados alguns padrões, como 
um dos poucos encontrados sobre as duas funções, hoje primordiais na rede, que a pesquisa pode mostrar.

\section{Referências}

ALBUQUERQUE, A. (1999) "Aqui você vê a verdade na tevê": a propaganda política na televisão. Niterói: MCII.

BLUMLER, J.; KAVANAGH, D. (1999). The third age of political communication: influences and features. Political Communication, 16, p. 209-230.

BORBA, F. (2012). A propaganda negativa: estratégia e voto nas eleições brasileiras. Tese apresentada ao Programa de Pós- Graduação em Ciências Humanas do Instituto de Estudos Sociais e Políticos (IESP).

ALDÉ, A.; BORGES, J. (2004). Internet, imprensa e as eleições de 2002: pautando notícias em tempo real. Logos, n. 21.

BRAGA, S. (2010). Podemos ter um(a) nov@ Obama? Perspectivas para o uso da internet no próximo pleito eleitoral brasileiro. Em Debate, n. 2, 2010, p. 10-18. ; NICOLÁS, M. A. (2011). O que a internet agrega às eleições? Um balanço inicial do uso da internet pelos candidatos aos governos estaduais e ao senado federal nas eleições brasileiras de outubro de 2010. In: Anais eletrônicos do IV Congresso Latino Americano de Opinião Pública do WAPOR. Belo Horizonte.

; ___ BECHER, A. (2013). Elites políticas e novas tecnologias: uma análise do uso pelos candidatos aos governos estaduais e ao senado nas eleições brasileiras de outubro de 2010. In: MARQUES, F,; SAMPAIO, R.; AGGIO, C (org.). Do clique à urna: internet, redes sociais e eleições no Brasil.

CERVI, E.; MASSUCHIN, M. G. (2011). HGPE e a formação da opinião pública no Brasil: análise das estratégias dos principais candidatos à presidência da república em 2010. In: Anais eletrônicos do IV Congresso Latino Americano de Opinião Pública do WAPOR. Belo Horizonte. Disponível em: <http://www.waporbh.ufmg.br/papers/Emerson_Urizzi_Cervi_2.pdf>. Acesso em: 20 de dezembro de 2011.

DADER, J. L. (2009). Ciberpolítica en los websites de partidos políticos: la experiencia de las elecciones de 2008 en España ante las tendencias transnacionales. Revista de Sociologia e Política, v. 17, n. 34.

; AYUSO, I. (2008). Las webs de partidos españoles 2004-2005: una investigación preliminar y de comparación europea, con una propuesta metodológica. In: CANEL, M. J. \& GURRIONERO, M. G. Estudios de Comunicación Política. Madrid: Universidad Complutense de Madrid..

DIAS, M. R. (2009) Coadjuvantes no próprio espetáculo: os partidos políticos na propaganda eleitoral brasileira. In: $33^{\circ}$ Encontro Anual da ANPOCS. 
DOMINGUEZ, E. C. (2005) Ciberdemocracia: presupuestos teóricos y estado de la cuestión según una revisión bibliográfica. Trabalho apresentado no III Congrés Internacional Comunicació i Realitát, p. 853-864.

FIGUEIREDO, M.; ALDÉ, A.; DIAS, H.; JORGE, W. (1998). Estratégias de persuasão em eleições majoritárias: uma proposta metodológica para o estudo da propaganda eleitoral. Rio de Janeiro: Instituto Universitário de Pesquisas do Rio de Janeiro.

GARCIA, R. (2005). Campanhas eleitorais brasileiras na internet. Dissertação de mestrado apresentada ao Departamento de Ciência Política do Instituto de Filosofia e Ciências Humanas da Universidade Estadual de Campinas.

GIBSON, R. K.; WARD, S. (2000). A proposed methodology for studying the function and effectiveness of party and candidate web sites. Social Science Computer Review, Durham, v. 18, n. 3, p. 301-319.

IASULAITIS, S. (2007). Internet e Propaganda Política no Brasil: limites e possibilidades. Estudos de Sociologia, v. 12, n. 23, p. 153-172.

. (2013). Modalidades de participação política em websites eleitorais: uma análise de fóruns discussão com uma proposta metodológica. In: MARQUES, F.; SAMPAIO, R.; AGGIO, C. Do clique à urna: internet, redes sociais e eleições no Brasil. Salvador: EDUFBA.

LAU, R. R.; SIGELMAN, L. (2000). Effectiveness Of Negative Political advertising. In: THURBER, J. A; NELSON, C. J.; DULIO, D. A. Crowded airwaves: campaign advertising in elections. Washington: Brookings Institution Press.

MANCINI, P.; SWANSON, D. L. (1995). Politics, media and modern democracy: an international study of innovations in electoral campaigning and their consequences. Westport: Praeger.

MANIN, B. (1995). As metamorfoses do governo representativo. In: Revista Brasileira de Ciências Sociais: Associação Nacional de Pós-Graduação e Pesquisa em Ciências Sociais, São Paulo, n. 29, ano 10.

MARQUES, F. J. (2004). Dimensões da ciberdemocracia: Conceitos e experiências fundamentais. Dissertação apresentada ao Programa de Pós-graduação em Comunicação e Cultura Contemporâneas da Universidade Federal da Bahia.

MARQUES, F. J.; SAMPAIO, R. (2011). Internet e eleições 2010 no Brasil: rupturas e continuidades nos padrões mediáticos das campanhas políticas online. Galáxia, n. 22, p. 208-221.

MARQUES, F. J.; SILVA, F. ; MATOS, N..(2011). Estratégias de Comunicação Política Online: Uma Análise do Perfil de José Serra no Twitter. Contemporanea (UFBA. Online), v. 9, p. 344-369.

MAZZOLENI, G. (2010). La comunicación política. Madrid: Alianza Editorial. 
NEWELL, J. L. (2001). Italian political parties on the web. The Harvard International Journal of Press/Politics, n. 6, p. 60-87.

NICOLÁS, M. A.; FRANÇA, S. T.; BRAGA, S. (2010). Mecanismos de participação nos websites dos candidatos a prefeito nas eleições de 2008 no Brasil. Trabalho apresentado no $7^{\circ}$ Encontro da ABCP, Recife.

NORRIS, P. (2001). Digital divide; civic engagement, information poverty, and the internet worldwide. Cambridge: Cambridge University Press.

PENTEADO, C.; FORTUNATO, I. Comunicação pela internet. A energia na campanha presidencial brasileira de 2010. (2011). In: Líbero, São Paulo. V. 14, n. 28, p. 77-90

SAMPEDRO; PÉREZ, F. (2009). Las elecciones generales españolas de 2008: “bipolarización antagónica” fomentada por intereses político-mediáticos y las nuevas tecnología. Rev. Sociol. Polít., v. 17, n. 34, p. 129-135.

STROMER- GALLEY, J. (2014). Presidential Campaigning in the internet age. Oxford: Oxford University Press.

TAVARES, C. (2013). "Para presidente, vote na gente": as personalidades presentes nos programas do PT e PSDB veiculados no horário eleitoral de 2002, 2006 e 2010. Dissertação apresentada para obtenção do título de mestre na Universidade Estadual de Ponta Grossa. Área de Ciências Sociais Aplicadas.

VACCARI, C. (2008). Italian parties' websites in the 2006 elections. European Journal of Communication, v. 23, n. 1, p. 69-77. 